\title{
Force feedback-based quality monitoring of the friction stir welding process utilizing an analytic algorithm
}

\author{
P. Rabe $^{1}$ (D) A. Schiebahn ${ }^{1}$ (D) U. Reisgen ${ }^{1}$ (I) \\ Received: 2 September 2020 / Accepted: 28 November 2020 / Published online: 9 December 2020 \\ (C) The Author(s) 2020
}

\begin{abstract}
The friction stir welding (FSW) process is known as a solid-state welding process, comparatively stable against external influences. Therefore, the process is commonly used with fixed welding parameters, utilizing axial force control or position control strategies. External and internal process disturbances introduced by workpiece, gap tolerance, tool wear, or machine/tool inadequacies are rarely monitored, and conclusions about the weld seam quality, based on the recorded process data, are not drawn. This paper describes an advancement, improving on research into the correlation of process force feedback events or gradual force changes and the resulting weld seam characteristics. Analyzing the correlation between examined weld sections and high-resolution rate force data, a quality monitoring system based on an analytic algorithm is described. The monitoring system is able to accurately distinguish sound welds from such with internal (void) and external (flash) defects.
\end{abstract}

Keywords Friction stir welding FSW · Quality monitoring · Force feedback

\section{Introduction}

The friction stir welding process, which was introduced and patented in 1991 by TWI, enables the reproducible joining of mainly nonferrous metals [1]. The joint formation based on intermixing of plasticized metals allows for firmly bonded welding of non-fusion weldable alloys, while at the same time increasing joint quality compared to fusion welding processes by eliminating the formation of metallurgical pores and minimizing distortion [2].

From the beginning of its industrial use until today, FSW has been used in applications requiring the joining of high performance alloys and minimization of distortion. Starting in 1993, NASA used FSW for the joining of lithiumcontaining Al-alloys for its space shuttle fuel tanks. FSW was the only way to reliably join this high strength-toweight ratio alloy and to achieve weld seam properties

Recommended for publication by Commission III - Resistance Welding, Solid State Welding, and Allied Joining Process

P. Rabe

rabe@isf.rwth-aachen.de

1 ISF - Welding and Joining Institute, RWTH Aachen University, Pontstr. 49, 52062 Aachen, Germany comparable to the mechanical properties of the base material to exhaust the alloy's potential [3].

FSW has spread further into industrial use, being employed to maximize material properties and save weight in car bodies and panels [4], as well as trains and ships [5] and entertainment electronics [6]. After the end of the patent protection in 2015, the following elimination of licensing costs [7] and the ever increasing trend towards light weight construction, the interest for further industrial applications spiked. While being regarded as a stable, reliable process, suitable monitoring, and tracing methods are in increasing demand. Commonly the static component of the axial process force can be used for process control, to further increase process stability [2]. First attempts at also utilizing the dynamic components of all three spatial process forces show a correlation with weld seam characteristics. Various avenues of research into force variation and cyclical components in time and frequency domain have been published, e.g., [8-11] with mixed success and industrial applicability. A mutual shortcoming of these works presents in the missing transferability to other joining challenges.

The presented work eliminates the influence of machine properties on the results and examines high-frequency process force feedback in the frequency domain, as well as in the time domain. Based on the observations, an analytic algorithm defining weld seam characteristics is derived. 


\section{Problem statement}

The empirically developed and integrated friction stir welding processes are generally regarded as stable and controllable, but they are also susceptible to external disturbances. Gap tolerances, material thickness variation, as well as surface condition and tool wear can have negative influences on the process. Currently, process quality is governed through control of the static component of the axial force, but the need for reliable inline monitoring of FSW weld seam quality cannot be fulfilled by today's process control strategy. Therefore, in current production processes, additional quality assessment is required downstream, which increases complexity, manufacturing time, and costs. With the increasing commercial relevance of FSW, the need for reliable and cost-efficient inline quality monitoring, which is immune to external disturbances, increases.

It is known that the process forces during FSW are composed of a static part and a dynamic component, which presents in a cyclical manner, corresponding to the rotational speed of the welding tool. This work examines the dynamic components of the FSW process forces and correlates force feedback events with weld seam features. To ensure unbiased results, the machine to be used is analyzed. The machine's static and dynamic properties are investigated to eliminate the influences of varying compliance or natural frequency agitation and dependent oscillation. The welding investigations are conducted for multiple tools with varying geometric properties and features. Process forces are recorded with high time and force resolution rates and internal weld seam features like tunnel defects and external defects like flash build up are determined through various investigations. Based on these investigations, correlations are derived and an analytic algorithm, analyzing weld seam quality is developed and implemented, allowing for quality monitoring of different weld challenges. Furthermore, the algorithm's need for costly equipment and processing power is reduced, so that it can be implemented as inline monitoring.

\section{Setup and investigation}

In order to evaluate the FSW process independent from the machine influence, it was determined that the machine characteristics for its static and dynamic behavior need to be identified prior to any welding measurements. For the FSW investigations, a FSW machine in portal design with a moving worktable was chosen for its high proposed rigidity and table position-independent compliance. The experiments were conducted on a Precision Technologies Group (PTG) Holroyd Ltd. Model 345C. The machine offers internal force measurements at reduced time and force resolution as well as Siemens Sinumerik ${ }^{\circledR}$ controls and a maximum axial load of $60 \mathrm{kN}$. To identify static machine behavior, a load was applied between working table and tool holder. The displacement of the tool holder relative to the working table was measured.
Fig. 1 Axial compliance of utilized welding machine, PTG $345 \mathrm{C}$

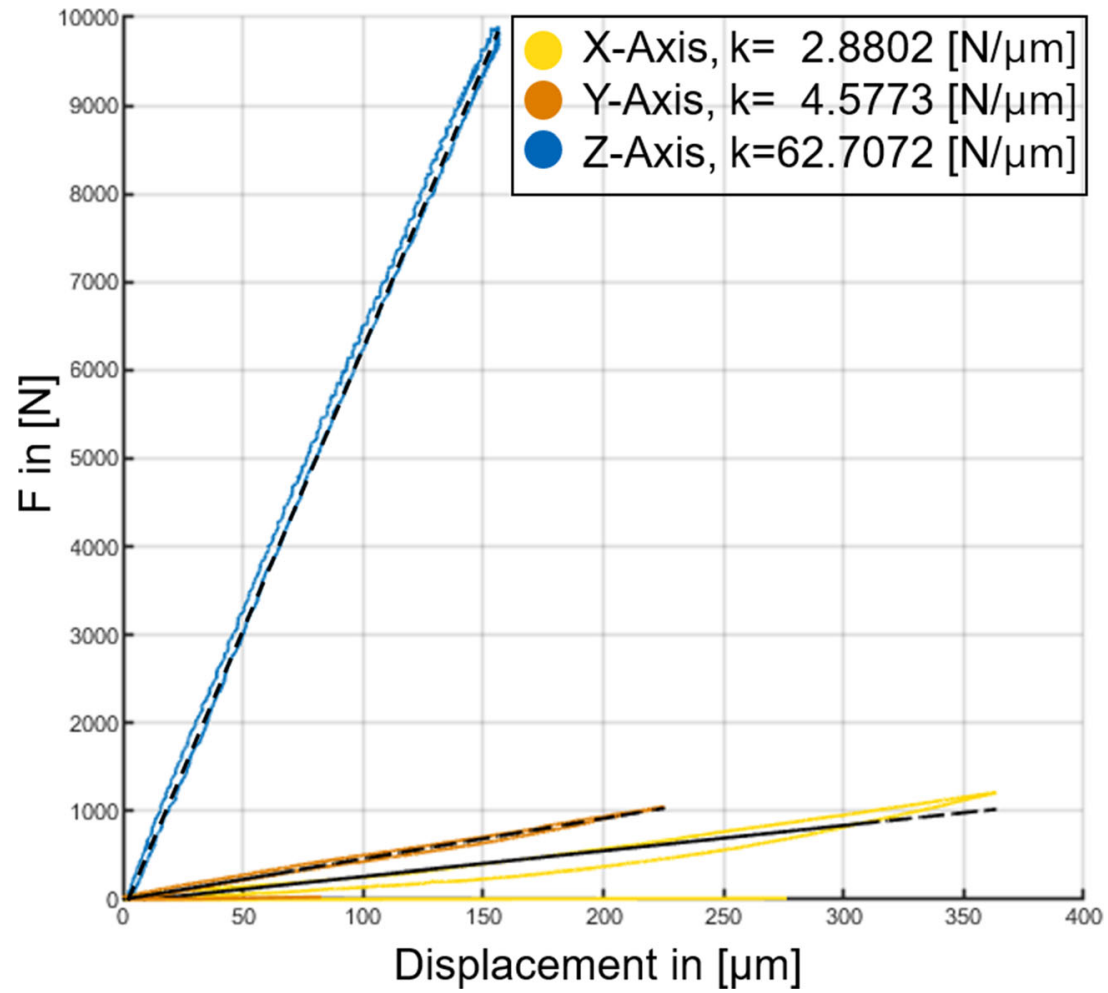




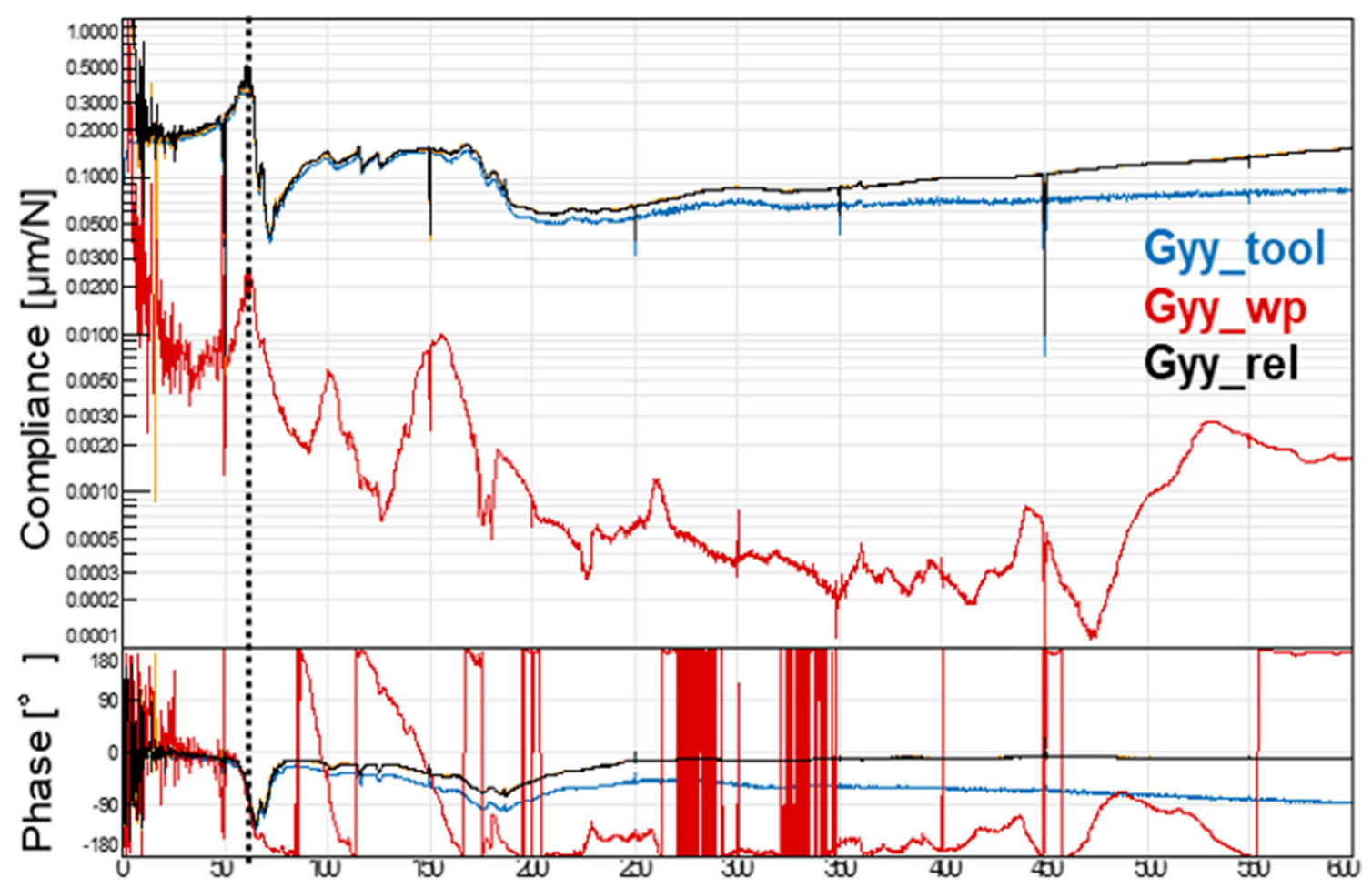

Fig. 2 FRF of PTG345C Y-axis, for tool (blue), workpiece (red), and relative oscillation (black) between tool and workpiece

Measurements were taken in all three spatial directions and repeated for different positions on the worktable. The table position had a negligible influence on the results. The axisdependent compliance is shown in Fig. 1.

The $\mathrm{X}$ - and $\mathrm{Y}$-axis were tested to $1 \mathrm{kN}$ and the $\mathrm{Z}$-axis was tested to $10 \mathrm{kN}$, relating to expected force ranges during welding. All tests show linear compliance behavior and small hysteresis. A significant dependency on load direction can be determined between the different axes. The stiff construction in spindle direction, experiencing the highest loads during welding, shows the lowest compliance. The general welding direction, $\mathrm{X}$-axis, shows the lowest stiffness. This result is due to its long stroke, $2000 \mathrm{~mm}$, as well as the combined compliance of B- and C-axis bearings and the linear drive. The machine's dynamic properties were measured by applying a multi frequency sinusoidal oscillation and measuring resulting oscillation and phase difference using accelerometers placed on the working table and tool holder. The resulting frequency response functions (FRF) can be used to identify critical natural excitation frequencies. These are defined through increased compliance and a corresponding phase drop of $>90^{\circ}$. The results of Xand $Z$-axis analyses indicate no critical frequencies. The FRF of the $\mathrm{Y}$-axis is depicted in Fig. 2. A natural frequency can be identified at $60 \mathrm{~Hz}$. While the identified natural frequency cannot be excited by the spindle directly, due to it exceeding the maximum spindle speed ( $2800 \mathrm{RPM} \triangleq 46,6 \mathrm{~Hz}$ ), excitation of the $\sim 60 \mathrm{~Hz}$ frequency band due to the first higher harmonic of a corresponding spindle speed of 1800 RPM needs to be monitored during welding experiments.
Process forces during welding experiments were recorded using a Kistler® multi-component measuring platform Type 9366CC. The platform is comprised of four pre-stressed piezo-sets and a 40-mm topping plate made of Al-alloy with a $10-\mathrm{mm}$ mild steel plate that serves as the working surface. Each set is capable of measuring forces in all three spatial directions. The measurement chain is completed by a multichannel charge amplifier, Type Kistler 5070A11100, and an $\mathrm{AD}$ converter. The measuring chain is capable of recording forces at $65 \mathrm{kHz}$ measuring frequency [12].

For the conducted experiments, a measuring frequency of $20 \mathrm{kHz}$ was used, as it was deemed sufficient for analysis in time and frequency domain. A Matlab® program was used to record the data and execute analysis.

For all welding experiment sheets of $3 \mathrm{~mm}$ thickness, Alalloy AW5754 ( $\left.\mathrm{AlMg}_{3}\right)$ were used in $\mathrm{H} 22$ rolling condition. The chemical composition of the used materials is shown in Table 1.

To define the influence of welding tool features and develop a monitoring system applicable to various welding

Table 1 Chemical composition of work piece alloy AW-5754 H22

Chemical properties [\%]

\begin{tabular}{llllllllll}
\hline $\mathrm{Al}$ & $\mathrm{Si}$ & $\mathrm{Fe}$ & $\mathrm{Cu}$ & $\mathrm{Mn}$ & $\mathrm{Mg}$ & $\mathrm{Cr}$ & $\mathrm{Zn}$ & $\mathrm{Ti}$ & Other \\
\hline 96.13 & 0.17 & 0.28 & 0.04 & 0.29 & 3.02 & 0.02 & 0.01 & 0.013 & $/$ \\
\hline
\end{tabular}




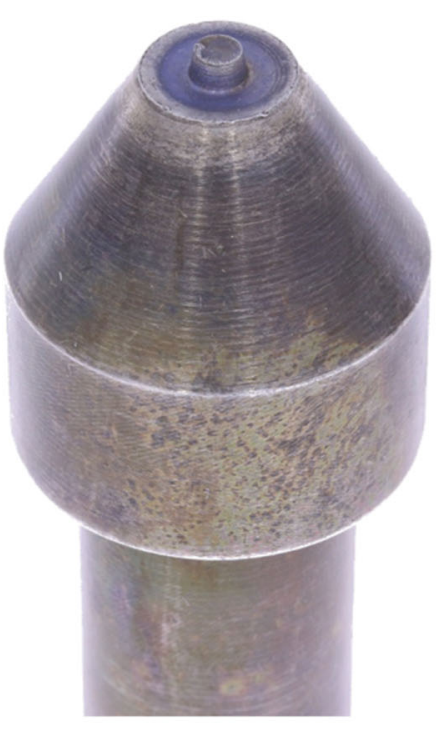

Tool 1

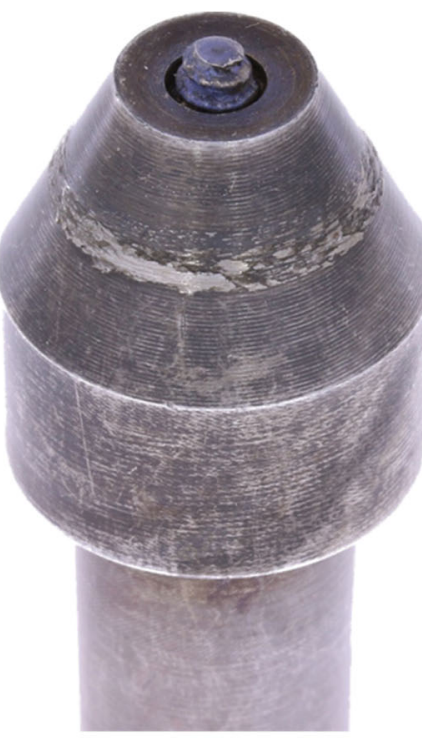

Tool 2

Fig. 3 Welding tools used during experimental investigation

challenges, two different tools were used. The tools along with their relevant geometric dimensions and features are depicted in Fig. 3. The tools will be referred to as tool 1 and tool 2, as shown. The distinguishing differences between the tools are the shoulder diameter, having significant influence on resulting forces and the pin profile, strongly increasing material transport, and increasing downward flow in tool 2 [13].

The welds were performed as blind welds with a fixed tilt angle of $1.6^{\circ}$. The weld length was $135 \mathrm{~mm}$ with a plunge rate of $80 \mathrm{~mm} / \mathrm{min}$ and a dwell time of $1 \mathrm{~s}$. Spindle direction was $\mathrm{Z}$ corresponding to downward material flow from the threads on tool 2. All welds were performed in position control mode with plunge depths relative to the machine coordinate system, so that these could be systematically varied. The experimental design of the changeable parameters is shown in Fig. 4.
The three distinct sets of experiments were chosen to determine influence factors on defect formation and to analyze feedback. Set 1 uses a fixed RPM/Feedrate relationship over a wide range of RPM. Sets 2 and 3 use fixed RPMs with increasing feed rates as the main excitation in FSW depends on tool rotational speed. The feed rate is increased to investigate internal void defect formation caused by insufficient heat input. The spindle speed of set 3 was chosen at 1800 RPM, as its first higher harmonic excites the machines previously identified natural frequency $(60 \mathrm{~Hz})$ and an increase in resulting osciallation is expected. The order of experiments was randomized, and for each parameter combination, experiments were performed with decreasing plunge depth until a sound weld and a defective weld were produced reliably. Each combination was repeated three times. Sample surfaces were assessed based on criteria
Fig. 4 Welding parameters used in the experiments

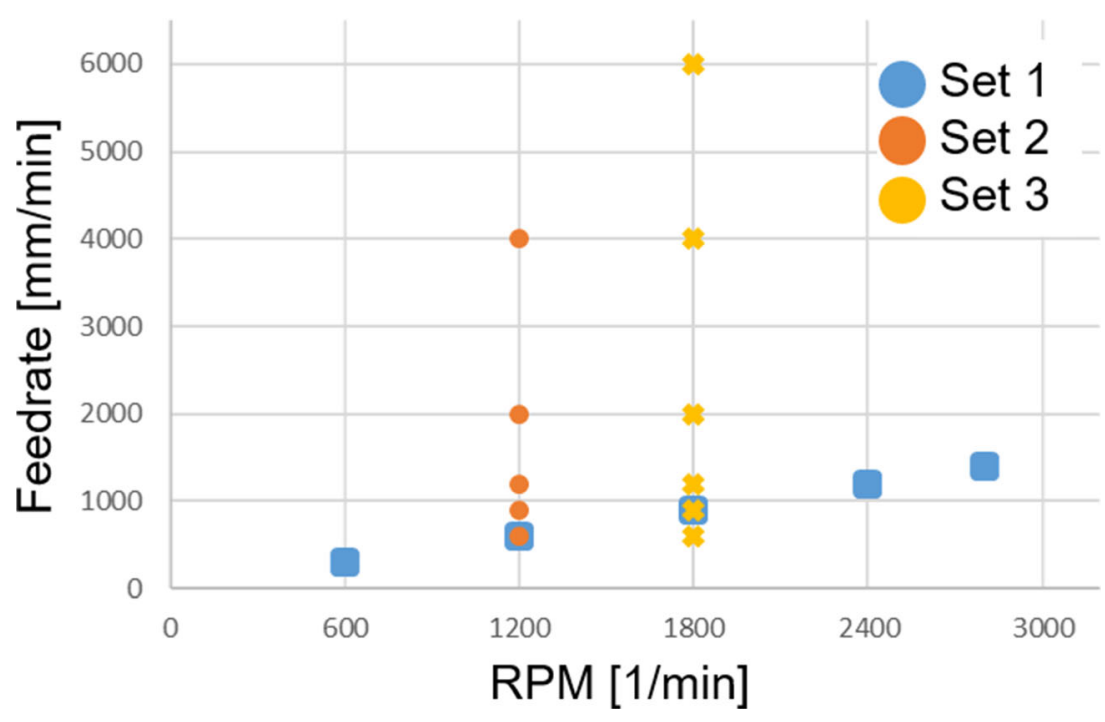


Table 2 Categorization of weld seam features

\begin{tabular}{ll}
\hline Weld seam feature & Category \\
\hline No feature/defect free & 0 \\
Flash & -1 \\
Tunnel defect (small) & 1 \\
Tunnel defect (large) & 2 \\
\hline
\end{tabular}

defined in ISO 25239-5 [14] and samples with open surface defects were discarded. Cross-sections were taken from all remaining welds, polished, etched with Keller's reagent, and investigated for internal defects. Each sample was then categorized into one of four categories. The categories are listed in Table 2 and are used as a basis for weld quality determination.

The distinction between category 1 and 2 is made based on acceptance level $\mathrm{C}$ for internal voids in the relevant ISO specification [14]. Category 1 refers to solid flash that cannot be easily brushed away, but rather constitutes material loss in the weld zone.

The categorization is then used to correlate data and extract weld quality information.

\section{Results and evaluation}

The recorded process forces can easiest be visualized in the time domain, as force over time for all spatial directions. An example correlating the forces to the weld seam surface is shown in Fig. 5.

This example visualizes the insufficiency of mean average axial force control described in the problem statement. It can be seen that after the run-in period (1), the average axial force is constant while the weld seam appearance changes (2). In section (3), the axial force deviates without significant influence on the weld seam appearance. In section (4), a drop in average axial force can be linked to an increase in surface waviness.

For examination in the frequency domain, fast Fourier transformation (FFT) was performed utilizing the functionality implemented in the Matlab ${ }^{\circledR}$ program. Due to the recording frequency of $20 \mathrm{kHz}$ and the Nyquist-Shannon theorem, oscillations up to $10 \mathrm{kHz}$ can be identified. For the following passage, FFTs of $1.5 \mathrm{~s}$ of weld data are used. These $1.5 \mathrm{~s}$ are taken from a steady-state process area, correlating to the spot of the analyzed cross-section. Figure 6 shows the frequency band $0-100 \mathrm{~Hz}$ for the axial force. According to [15], internal void defects are indicated through high amounts of low frequency oscillation.

The amplitude (Y-axis) is limited to $80 \mathrm{~N}$ in order to better identify low intensity amplitudes. The spindle speeddependent excitation frequency $20 \mathrm{~Hz}$ (1200 RPM) and its higher harmonics can be identified. The parameter difference between the samples is a $0.1-\mathrm{mm}$ increase in plunge depth, avoiding the void defect formation found in a). The amplitude below the excitation frequency gives no indication towards the defect formation. The frequency bands $100-1000 \mathrm{~Hz}$ and $1000-10,000 \mathrm{~Hz}$ were examined for all three spatial directions and no clear correlation between increased or decreased oscillation intensity and weld seam features could be found. This includes careful examinations of increased intensity around frequencies close to the identified natural frequencies of the machine and testing setup.

As the analysis of the frequency domain yielded no expedient results, investigations were continued in the time domain, examining dynamic process force components based on prior publications and research. According to [8], a correlation between the mean average lateral force (Y-axis) and void defect formation exists. The influence of the lateral force shift towards the advancing side is examined in Table 3 for welds performed with the stated parameters using tool 1 .
Fig. 5 Recorded process forces and surface appearance for sample 90; Tool 1-1800 RPM $900 \mathrm{~mm} / \mathrm{min}$

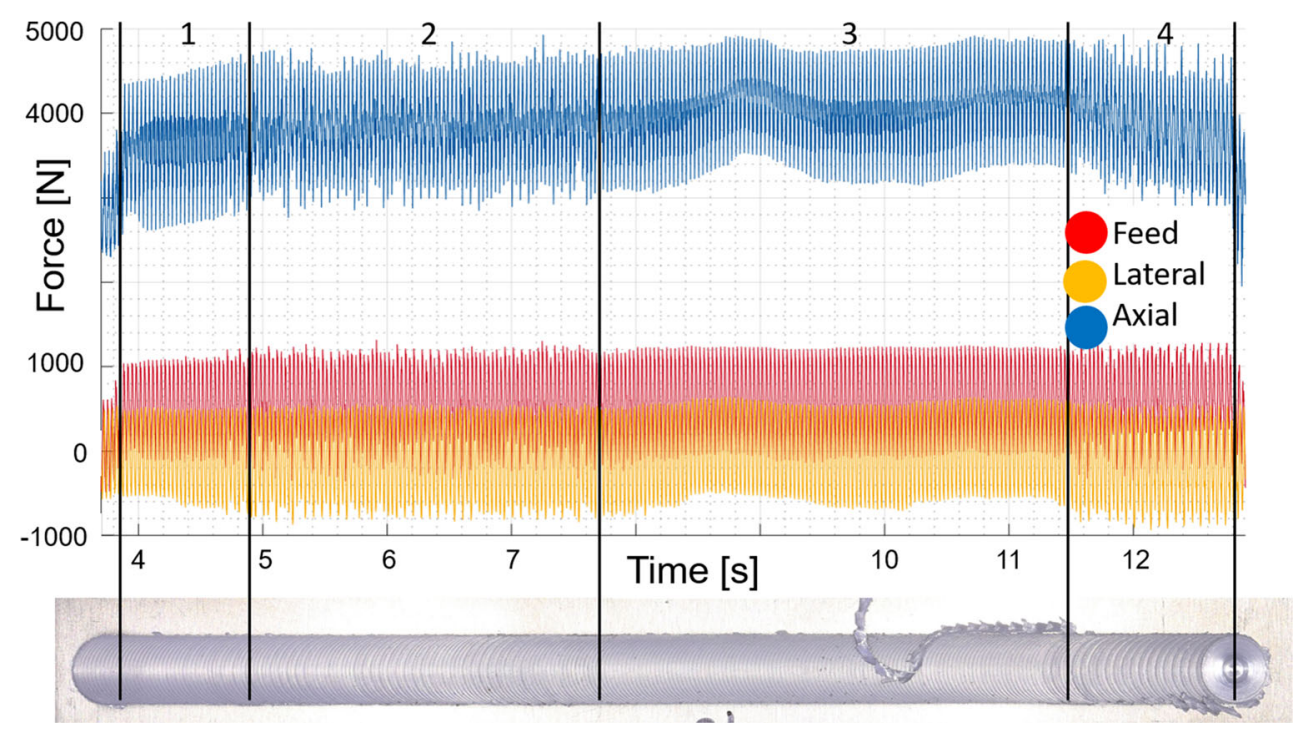



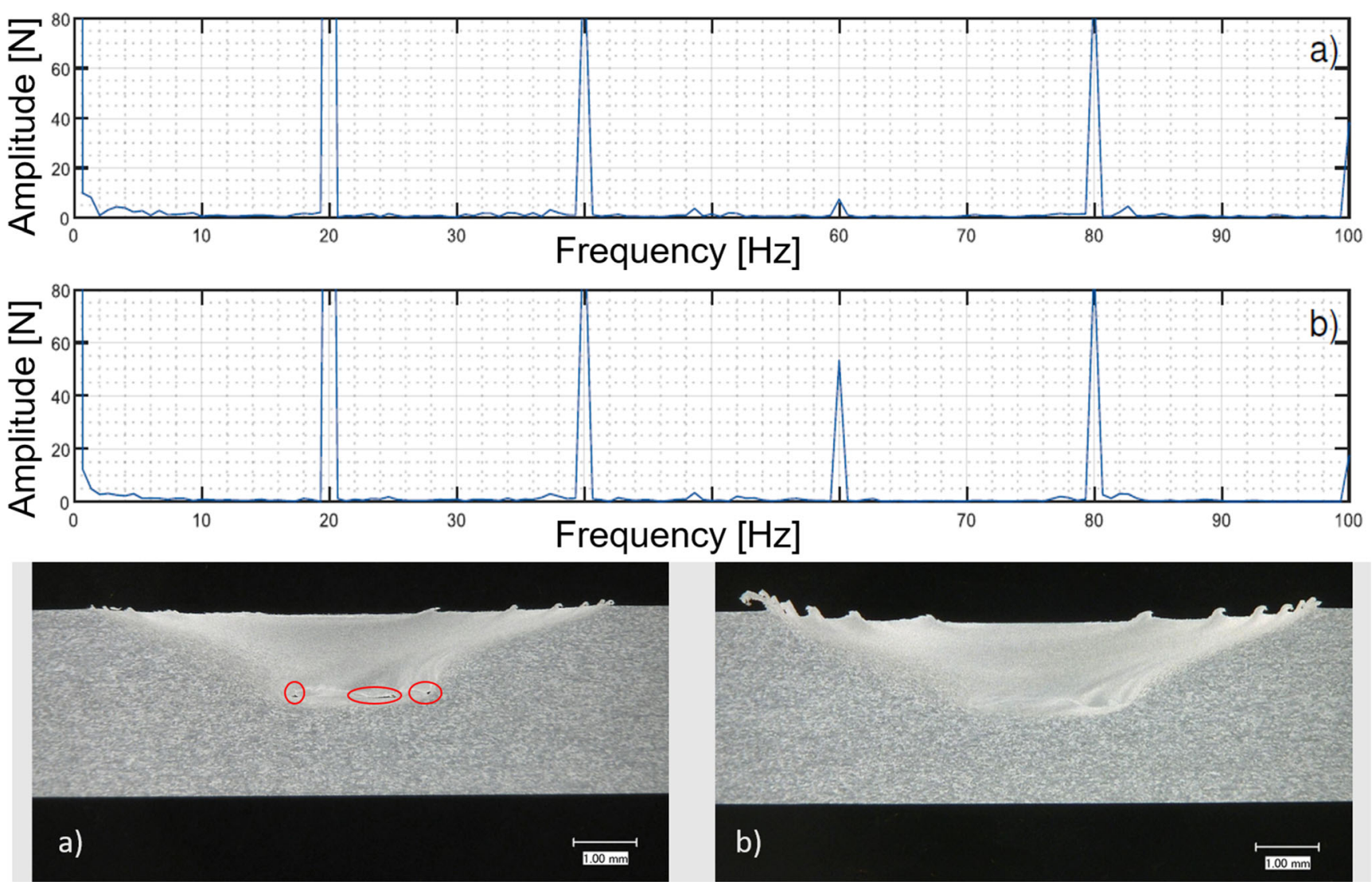

Fig. 6 Amplitude spectra of axial force and cross-sections of sample 30 (a) and 32 (b)

Over the range of tested parameters, no correlation of mean average lateral force and void defect formation can be found. The average lateral force generally inversely correlates with specific energy input $[\mathrm{J} / \mathrm{mm}]$ but shows no significant variation during defect formation. The lateral force amplitude cannot be used to identify void defects either as it does not correlate with any given parameters. It can be used as an indicator for excessive flash, as with increasing flash the amplitude drops by up to $30 \%$.

[2] graphed the axial force over spindle torque to identify weld seam features. Smooth, uniform graphs indicate sound welds, whereas scattered plots indicate defects. Based on this approach, the force graphs of all welds performed during the investigation were mapped for the three possible force combinations. Figure 7 shows exemplary graphs for two samples. In the graphs, $0.5 \mathrm{~s}$ of data are mapped and the uniformity of the graphs corresponds well with weld quality.
The scattered graphs for sample 46 indicate void defect formation, which was confirmed by the cross-section examination. The clearest indication is given through the feed force (Fx) over lateral force (Fy) graphing. When graphed threedimensionally, the time-dependent variation can be visualized and the defect formation located. For sample 46, varying distances between force oscillations can be identified for the defective weld regions. Based on the identified correlation, a detection algorithm was developed. The algorithm identifies each tool revolution and separates the measurement data accordingly. The extracted signal is shifted by up to $\pm 0.5 \%$ minimizing the difference to account for offset of measurement rate and excitation frequency. Subsequently, the force data of each spatial direction is subtracted from itself with a shift of one period (one tool revolution) calculating the force difference for each discrete measurement point at the
Table 3 Influence of average lateral force on void defect formation

\begin{tabular}{lllllll}
\hline No. & $\begin{array}{l}\text { RPM } \\
{[1 / \mathrm{min}]}\end{array}$ & $\begin{array}{l}\text { Feed }[\mathrm{mm} / \\
\mathrm{min}]\end{array}$ & $\begin{array}{l}\text { Depth } \\
{[\mathrm{mm}]}\end{array}$ & $\begin{array}{l}\text { Avg lateral } \\
\text { force }[\mathrm{N}]\end{array}$ & $\begin{array}{l}\text { Amplitude lateral } \\
\text { force [N] }\end{array}$ & $\begin{array}{l}\text { Void defect } \\
\text { [yes/no] }\end{array}$ \\
\hline 57 & 1800 & 900 & 1.6 & 34.1 & 1358 & No \\
59 & 1800 & 900 & 1.5 & 41.9 & 1305 & Yes \\
47 & 1200 & 1200 & 1.7 & 334.7 & 910 & No \\
53 & 600 & 300 & 1.7 & -40.9 & 1329 & Yes \\
\hline
\end{tabular}


Fig. 7 Graphed force relationships, red $(\mathrm{Fx} \leftrightarrow \mathrm{Fy}$ ), yellow $(\mathrm{Fz} \leftrightarrow \mathrm{Fy})$, and blue (Fz $\leftrightarrow \mathrm{Fx}$ ) for a sample with void defect (46) and a sound weld (48)
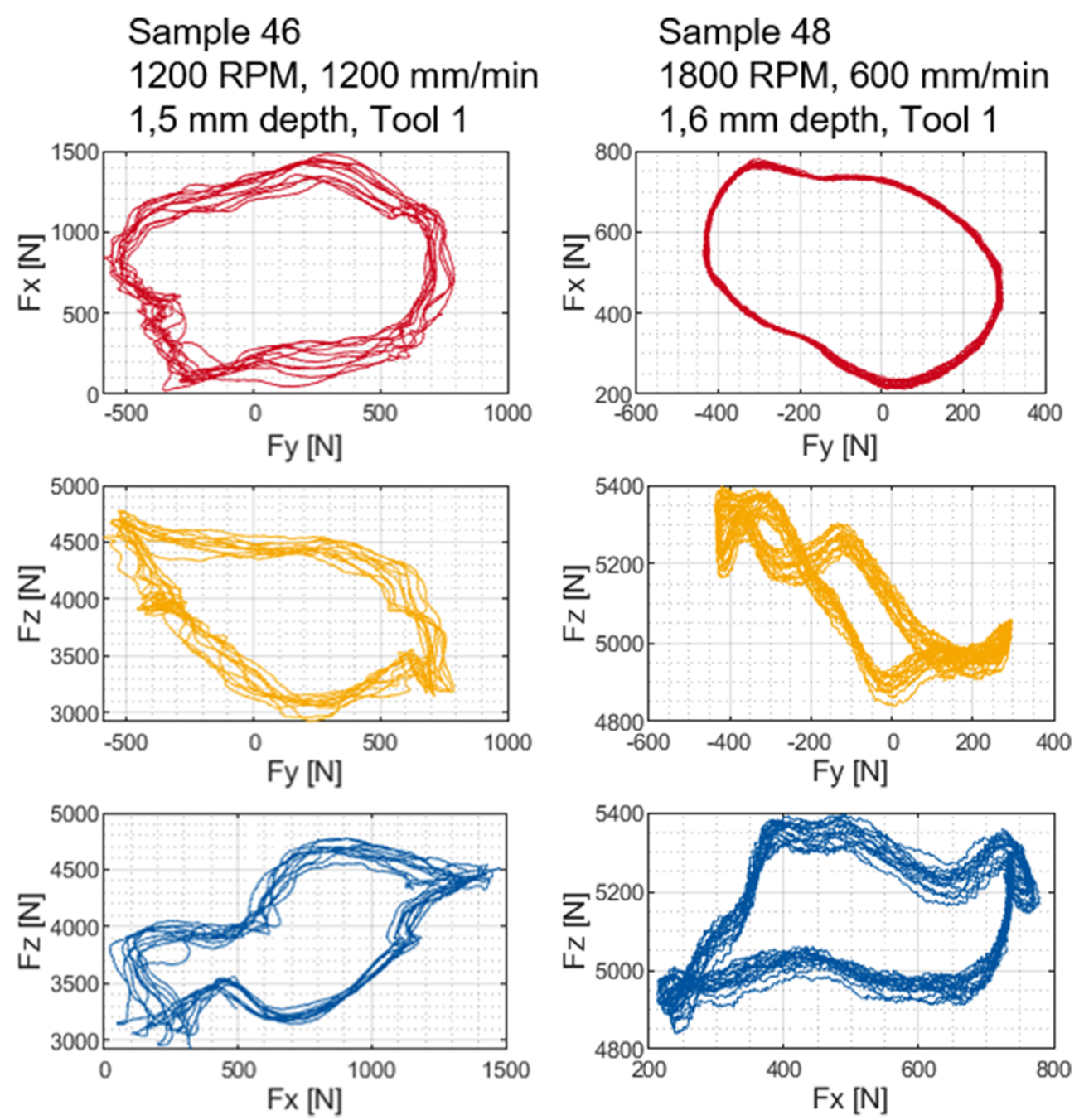

measurement rate of $20 \mathrm{kHz}$ and logging the results. An exemplary depiction of the operation and results is shown in Fig. 8. Along with the dynamic force variation, the phase difference and shift are also analyzed. Phase shift is determined for every force signal and every revolution by calculating the necessary shift to minimize force difference per revolution and expressing the resulting fraction in degrees of phase shift. The phase difference between two force signals is calculated by evaluating the phase difference of the best sinusoidal fit for each revolution.

All spatial forces, phase shifts and combinations result in nine different graphs for each weld. An example of all resulting graphs for a weld with void formation is shown in Fig. 9.

Phase difference between two force signals is constant as varying influences are seen with little variance over all force signals. The phase shift for each signal generally corresponds with defect initiation, but cannot be used as a reliable indicator as the shift is usually minimal and rarely exceeds $1^{\circ}$. While it correlates with defect initiation, the phase shift offers little indication to defect persistence. The deviation in the force signal offers the clearest correlation and time-dependent indication of defect formation. While all three force signals oscillate with spindle frequency and often show disturbances due to defect formation, only the feed force adequately determined void formation through force deviation per revolution. For this defining metric, a force deviation threshold was identified for each of the used tools. Furthermore, for the thread-less tool 1 a secondary threshold was identified to determine flash formation. Due to the tool shoulder diameter and the resulting forces as well as the altered material flow induced by the thread, the identification threshold and determination accuracy vary between the investigated tools.

\section{Discussion}

During the investigation, various methods of force data analysis have been tested for their potential for FSW weld seam quality monitoring. Most of the tested methods could not be 


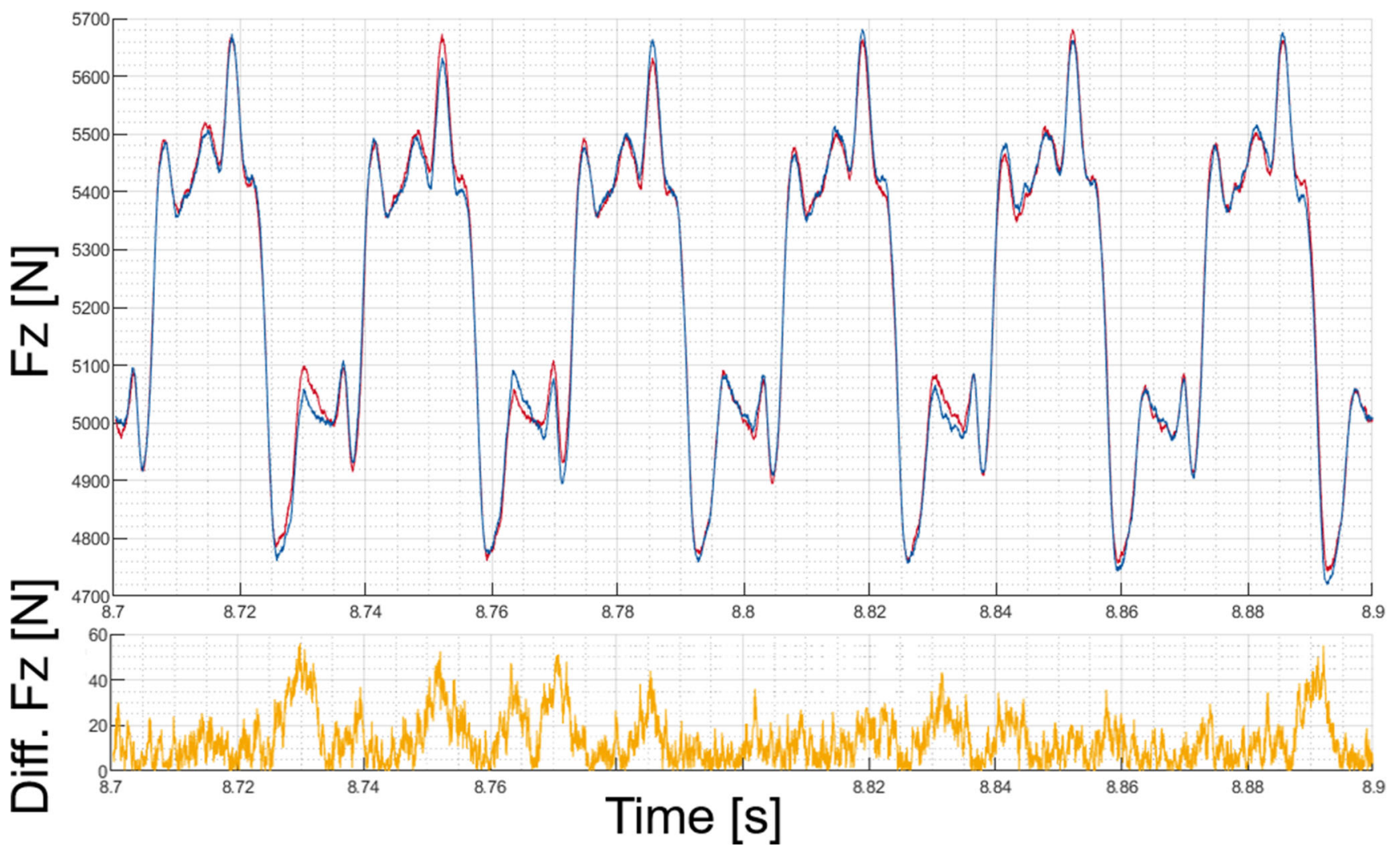

Fig. 8 Graph of Z-force difference over six revolutions with a one revolution time shift

validated with the conducted tests and the investigated sample size of more than 200 welds. Based on [2], an algorithm calculating force deviation was developed. For each of the investigated tools, an indication threshold was defined. The
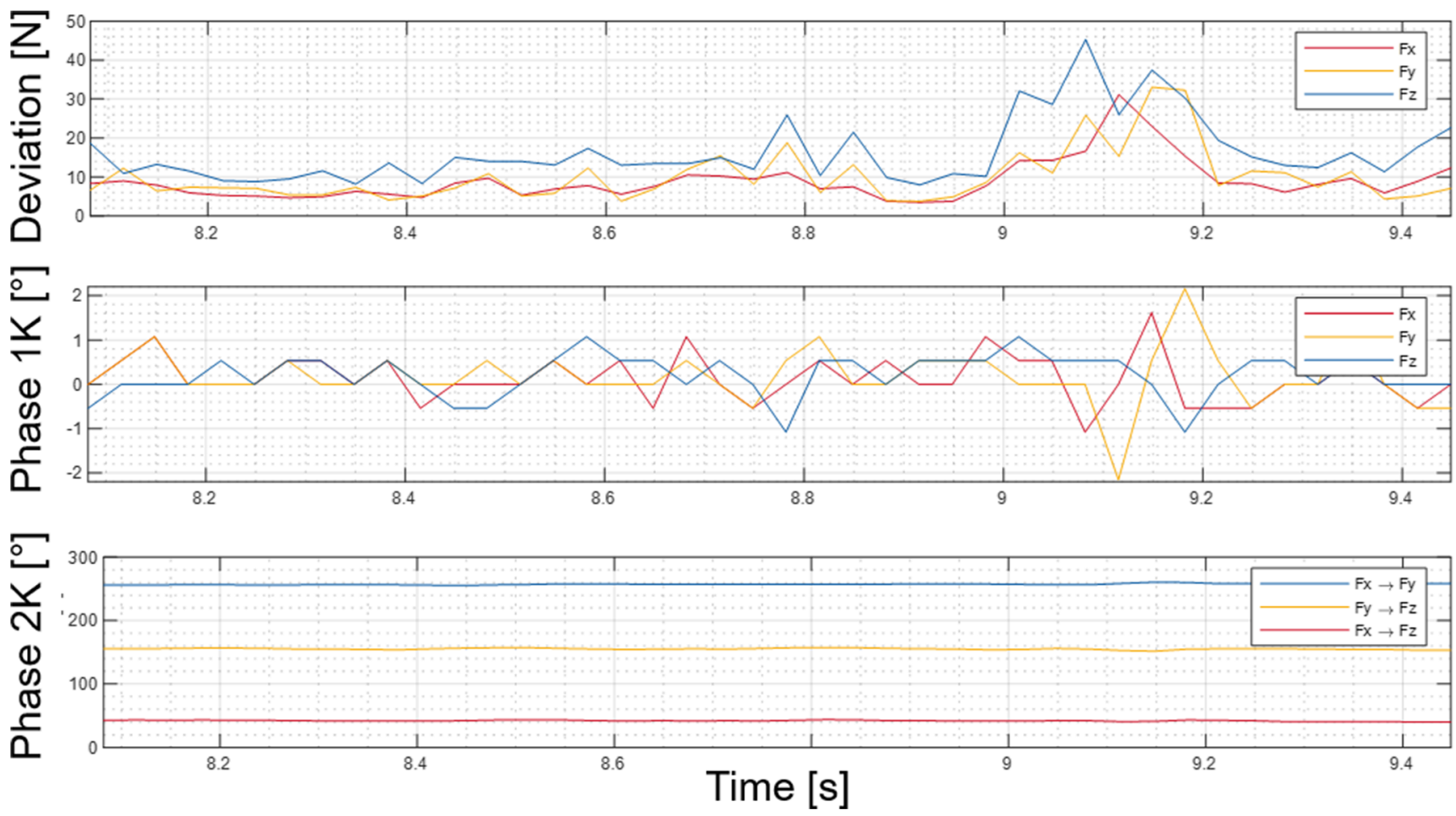

Fig. 9 Output of analysis algorithm; 1. Force deviation, 2. Phase shift within force signal, 3. Phase shift between two force signals 
Fig. 10 Resulting weld seam classification for tool 1 categorized by Table 2 including defect detection threshold

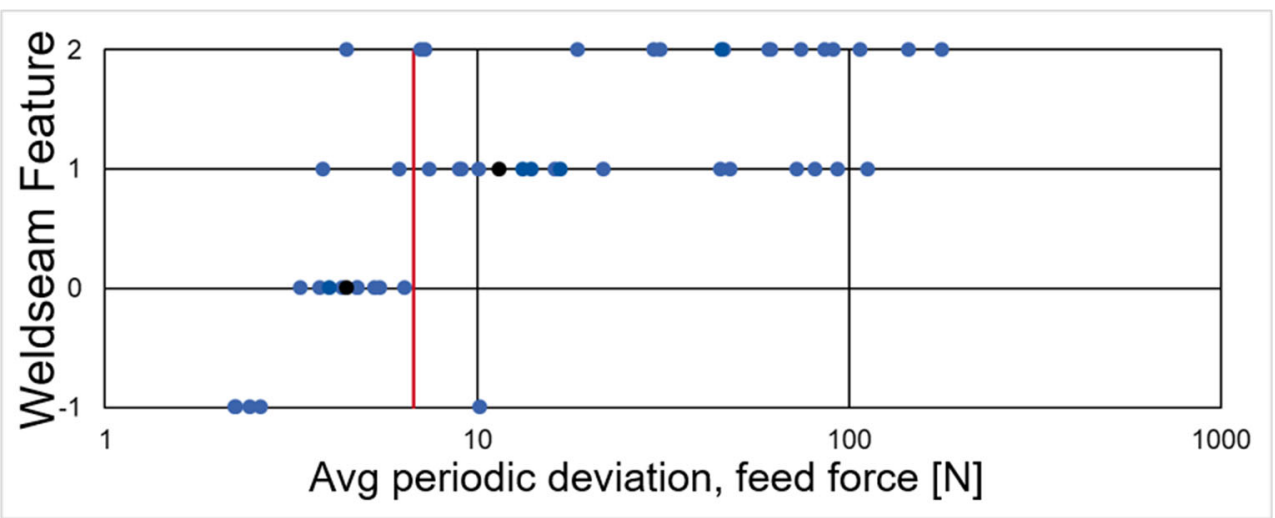

threshold for the featureless tool 1 was determined to be $6.75 \mathrm{~N}$. This yielded a determination accuracy of $91.8 \%$ over 49 investigated cross-sections, with 1 not detected void defect outside category C [14], 2 undetected smaller void defects, and 1 false positive. The resulting classification is shown in Fig. 10.

The threaded pin on tool 2 increases material flow and introduces a position-dependent shift in flow direction, thereby also increasing force deviation. The increased deviation aids in threshold determination allowing for $98.1 \%$ determination accuracy over 53 investigated samples at a $50.0 \mathrm{~N}$ threshold. The results are shown in Fig. 11.

Each of the classification results can alternatively be visualized in a time-dependent manner comparable to Fig. 9, thereby enabling position-dependent weld seam quality assessment. Furthermore, this method can be implemented on the live data stream providing real-time quality monitoring for the given weld conditions. As classifications are derived in the time domain, the measuring frequency can thus be reduced to decrease implementation requirements. Promising results have been achieved with recording frequencies as low as $1 \mathrm{kHz}$.

Based on the conducted investigations and presented results, the system will be further developed to increase understanding of threshold variance and determine proper conditions for blind and lap welds as well as various sheet metal thicknesses and alloys.

\section{Conclusion}

The present work evaluated various methods of process feedback-based defect detection for FSW. Using the recorded data for different tools and blind welds in AW5754 H22, multiple published nondestructive testing and monitoring methods were investigated and could not be validated over a sample size exceeding 200 welds. An algorithm based on [2] was developed and refined. The algorithm examines feed force deviation during the steady state of the welding process. A tool-dependent threshold was introduced, correctly determining $92 \%$ and $98 \%$ of weld features for a thread-less and a threaded tool, respectively. Time-dependent visualization of the results enables not only defect detection but also location and in-process monitoring. At the current development state, implementation for threaded pins is more realistic, as increased material flow offers higher feedback forces and increased variance during defect formation.

For further industrial applicability, the threshold formation needs to be generalized and adapted for various joint geometries and sheet thicknesses. Furthermore to enable detection on
Fig. 11 Resulting weld seam classification for tool 2 categorized by Table 2 including defect detection threshold

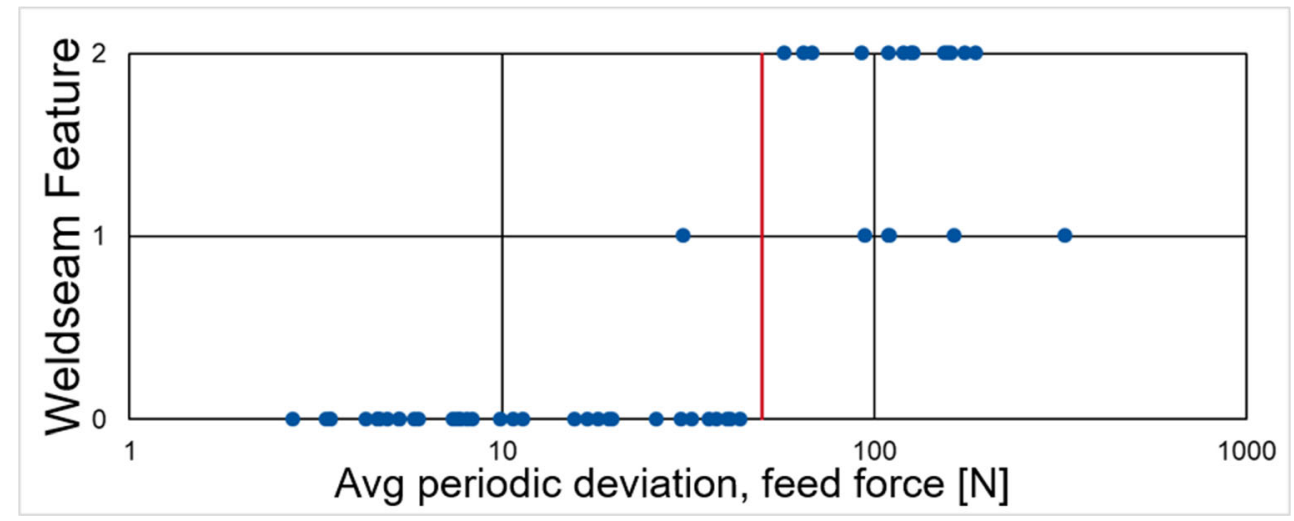


existing machinery, the required data rates need to be reduced. Due to the simple required calculation, implementation as online detection is seen as a viable option.

Acknowledgements Open Access funding enabled and organized by Projekt DEAL. The presented investigations were carried out at RWTH Aachen University and funded by the Deutsche Forschungsgemeinschaft (DFG, German Research Foundation) under Germany's Excellence Strategy - EXC 2023 Internet of Production - 390621612. The sponsorship and support is gratefully acknowledged. Experiments were performed at the Welding and Joining Institute (ISF) with support of the Machine Tool Laboratory (WZL).

Open Access This article is licensed under a Creative Commons Attribution 4.0 International License, which permits use, sharing, adaptation, distribution and reproduction in any medium or format, as long as you give appropriate credit to the original author(s) and the source, provide a link to the Creative Commons licence, and indicate if changes were made. The images or other third party material in this article are included in the article's Creative Commons licence, unless indicated otherwise in a credit line to the material. If material is not included in the article's Creative Commons licence and your intended use is not permitted by statutory regulation or exceeds the permitted use, you will need to obtain permission directly from the copyright holder. To view a copy of this licence, visit http://creativecommons.org/licenses/by/4.0/.

\section{References}

1. Patent: B23K 20/12, B29C 65/06, 10.06 .1993

2. Luhn T (2013) Prozessdiagnose und Prozess-Überwachung beim Rührreibschweißen, Pro Business, ISBN: 97838863869632 , Ilmenau

3. https://www.nasa.gov/sites/default/files/104835main friction.pdf Checked: 08.07.2020. Accessed 7 De 2020

4. https://media.daimler.com/marsMediaSite/en/instance/ko/ Aluminium-bodyshell-in-the-new-Mercedes-Benz-SL-Under-the- bottom-line-140-kilos-lighter.xhtml?oid=9817820, Checked: 08 . 07.2020. Accessed 7 De 2020

5. Kallee SW (2010) Friction stir welding, Industrial Applications of friction stir welding, Elsevier, https://doi.org/10.1533/ 9781845697716.1.118

6. https://appleinsider.com/articles/12/10/24/apple-slims-down-imac 40-with-friction-stir-welding-ditching-the-disc-drive Checked: 24. 09.2019. Accessed 07 Dec 2020

7. Patent: A2182719 (A1), 05.10 .1995

8. Jene T (2008) Entwicklung eines Verfahrens zur prozessintegrierten Prüfung von Rührreibschweißverbindungen des Leichtbaus sowie Charakterisierung des Ermüdungsverhaltens der Fügungen, Werkstoffkundliche Berichte Band 21, Kaiserslautern

9. Burford D, Boldsaikhan E, Wiley A (2012) Early detection of volumetric defects using e-NDE during friction stir welding, 9th International Friction Stir Welding Symposium. The Von Braun Center, Huntsville, Alabama

10. Hattingh DG, van Niekerk TI, Blignault C, Kruger G, James MN (2004) Analysis of the FSW force footprint and its relationship with process parameters to optimise weld performance and tool design. Weld World 48:50-58. https://doi.org/10.1007/BF03266414

11. Baraka A, Panoutsos G, Cater S (2016) Real-time quality monitoring for friction stir weldingAA2219-T845aerospace aluminium alloy via model-based spectralanalysis, 11 th International Symposium on Friction Stir Welding, Sheffield

12. Kistler, Betriebsanleitung Mehrkomponenten-KraftmesselementBausatz Typ 9366CC, Kistler Gruppe, 2009

13. Banik A, Deb Barma J, Saha SC (2020) Effect of threaded pin tool for friction stir welding of AA6061-T6 at varying traverse speeds: torque and force analysis. Iran J Sci Technol Trans Mech Eng 44: 749-764. https://doi.org/10.1007/s40997-019-00289-w

14. ISO 25239-5:2020 Friction stir welding -Aluminium- Part 5: Quality and inspection requirements

15. Gebhard P (2011) Dynamisches Verhalten von Werkzeugmaschinen bei Anwendung für das Rührreibschweißen, Herbert Utz Verlag, München

Publisher's note Springer Nature remains neutral with regard to jurisdictional claims in published maps and institutional affiliations. 